\title{
Model free Multiple Heating Rate Degradation Kinetic Studies of Modified Celluloses
}

\author{
SATISH KUMAR ${ }^{1}$, MAHESH KUMAR ${ }^{2}$, SOHAN LAL ${ }^{3}$, \\ SANDEEP KUMAR $^{4}$ and SANJIV ARORA ${ }^{3 *}$
}

${ }^{1}$ Department of Chemistry, University College, Kurukshetra University, Kurukshetra-136119, India

${ }^{2}$ Department of Chemistry, Mukand Lal National College, Yamuna Nagar-135001, India

${ }^{3}$ Department of Chemistry, Kurukshetra University, Kurukshetra-136119, India

${ }^{4}$ Department of Physics, Hindu College, Sonipat-131001, India

sanjivkuk@yahoo.co.in

Received 20 September 2014 / Accepted 17 October 2014

\begin{abstract}
The present paper depicts about the synthesis of cellulose ethyl ammonium thiophosphate (CEASP) and its metal complexes with $\mathrm{Cd}$, Mo and Ce. CEASP and its metal complexes have been characterized by infrared (IR), X-ray diffraction (XRD) and energy dispersive X-ray spectroscopy (EDXS) studies. The surface morphology of samples has been premeditated by means of scanning electron microscopy (SEM). The thermal studies of samples have been carried out at multiple heating rates $2,5,10$ and $20{ }^{\circ} \mathrm{C} \mathrm{min}^{-1}$ from ambient to $700{ }^{\circ} \mathrm{C}$ in nitrogen atmosphere. Nonisothermal model free kinetic methods have been used to calculate activation energy of samples i.e. Friedman, Ozawa-Flynn-Wall (O-F-W) and modified Coats- Redfern. The activation energy of samples lie in range $72-282 \mathrm{~kJ} \mathrm{~mol}^{-1}$. Thermal study shows that initial degradation temperature of CEASP and its metal complexes decreases and there is abrupt increase in char yield of synthesized samples as compared to pure cellulose. These and other related information suggest that such type of derivatisation could be proved a good flame retardant for cellulose.
\end{abstract}

Keywords: Cellulose, Model Free Kinetics, Flame Retardant, Activation energy

\section{Introduction}

Textile is very essential in modern living condition. It is not only essential for apparels but also for modern furnishing for grace and style. However, cheap element of textile is either cotton or polymer which is both flammable and combustive. It is therefore the need of our combat these characteristics of polymer either through chemical treatment or inventing new compound of fibre. The following paper is an attempt in that direction. Cellulose is the most abundant naturally occurring polymer that is used for apparels and also for modern furnishing to decorate interiors of buildings. Cellulose undergoes degradation on ignition, forming combustible volatile compounds mainly laevoglucosan that result in propagation of 
fire causing injuries, fatalities and huge losses ${ }^{1}$. So in order to reduce fire hazards the cellulose is modified that can be proved as good flame retardant ${ }^{2,3}$. There is sturdy relation between flame retardancy of a substance with char yield as it acts as a protective barrier that seals the substract from the surrounding heat that controls the flame spread. And also higher the char yield; the better will be the flame retardant character.

In this regard, Singh et al. ${ }^{4}$ and Dahiya et al. ${ }^{5}$ reported the thermal studies of cellulose modified with cresyldichlorothiophosphates, arylphosphorodichloridites, respectively. Dahiya et $a l .{ }^{6}$ studied the thermal properties of cellulose benzylthiophosphate and its metal complexes and calculated the activation energy of samples using TG data. Consequently, thermal degradation of phosphorylated cellulose like cellulose 2-chlorophenylthiophosphates, cellulose arylphosphates and their metal complexes were studied ${ }^{7}$. However, authors have used single heating rate methods e.g. Broido for calculation of kinetic parameters. These methods are facing disapproval due to problematic procedures and unreliable results 8,9 . Consequently the use of multiple heating rate methods i.e. Ozawa-Flynn-Wall $(\mathrm{O}-\mathrm{F}-\mathrm{W})^{10,11}$, Friedman ${ }^{12}$ and modified Coats-Redfern ${ }^{13}$ are preferred and used in this paper.

In the present study, cellulose ethyl ammonium thiophosphate (CEASP) and its metal complexes with $\mathrm{Cd}$, Mo and $\mathrm{Ce}$ have been synthesized. The samples have been characterized by IR, XRD, EDXS studies. The surface morphology of samples has been premeditated by means of SEM. Thermal properties of samples have been studied by TG, DTG techniques in nitrogen atmosphere with a view to calculate degradation activation energy $(\mathrm{Ea})$ values at various degree of conversions using model-free methods.

\section{Experimental}

Cellulose was supplied by Acros Organics USA. Cadmium nitrate tetrahydrate $\left(\mathrm{Cd}\left(\mathrm{NO}_{3}\right)_{2} .4 \mathrm{H}_{2} \mathrm{O}\right)$, diammonium molybdate tetrahydrate $\left.\left(\mathrm{NH}_{4}\right)_{2} \mathrm{Mo} .4 \mathrm{H}_{2} \mathrm{O}\right)$ and ceric ammonium nitrate $\left(\mathrm{Ce}\left(\mathrm{NH}_{4}\right)\left(\mathrm{NO}_{3}\right)\right)$ were supplied by Himedia Lab $(\mathrm{P})$ Ltd. Mumbai, India.

Synthesis of CEASP and its metal complexes

$2 \mathrm{~g}$ of cellulose mercerized with $10 \% \mathrm{NaOH}$ solution and pyridine (Py). The mercerized cellulose was taken in $250 \mathrm{~mL}$ two neck round bottom (RB) flask that was fitted with water condenser having guard tube containing solid $\mathrm{CaCl}_{2}$ and its another end was fitted with septum. RB flask was cooled at ice salt mixture to $0{ }^{\circ} \mathrm{C}, 9.0 \mathrm{~mL}$ phosphorus oxychloride $\left(\mathrm{POCl}_{3}\right)(0.1 \mathrm{~mol})$ has been injected through septum followed by addition of $6 \mathrm{~mL}$ ethyl alcohol $(0.1 \mathrm{~mol})$ with constant stirring at $0{ }^{\circ} \mathrm{C}$ for $1 / 2 \mathrm{~h}$. Further $0.6 \mathrm{~g}$ thiourea $\left(\mathrm{NH}_{2} \mathrm{CSNH}_{2}\right)$ $(0.1 \mathrm{~mol})$ was added to the reaction mixture and refluxed on oil bath at $125^{\circ} \mathrm{C}$ for $24 \mathrm{~h}$. The resulting product was filtered, washed with hot water and dried in vacuum over $\mathrm{P}_{2} \mathrm{O}_{5}$. This resulting product was named as CEASP.

The metal complexes of CEASP were prepared via consistent shaking of $2 \mathrm{~g}$ of CEASP with $100 \mathrm{~mL}$ of $5 \%$ aqueous solutions of $\mathrm{Cd}\left(\mathrm{NO}_{3}\right)_{2} .4 \mathrm{H}_{2} \mathrm{O},\left(\mathrm{NH}_{4}\right)_{2} \mathrm{Mo} .4 \mathrm{H}_{2} \mathrm{O}$ and $\mathrm{Ce}\left(\mathrm{NH}_{4}\right)\left(\mathrm{NO}_{3}\right)$ for $72 \mathrm{~h}$ at room temperature, separately. Subsequently the complexes were filtered, washed thoroughly with water and dried in vacuum over $\mathrm{P}_{2} \mathrm{O}_{5}$. The synthesized complexes were named as CEASP-Cd, CEASP-Mo and CEASP-Ce depending upon the type of metal used.

\section{Characterization Techniques}

IR study

Cellulose and all prepared samples have been characterized by using ABB FTIR spectrophotometer over the frequency range of $4000-500 \mathrm{~cm}^{-1}$. The samples were oven dried, mixed with $\mathrm{KBr}$ in a ratio of 1:200 (w/w) and pressed under vacuum to form pellets. 
Scanning electron microscopy (SEM) and energy dispersive $x$-ray spectroscopy (EDXS) analysis

The surface morphology of synthesized samples was studied by scanning electron microscopy (SEM, model: Zeiss EVO MA 10) and elements present in the matrix were confirmed by energy dispersive X-ray spectroscopy (EDXS, model: Oxford INCA 250).

\section{$X$-ray diffraction study}

The crystalline phase has been analyzed using a D-8 advance powder X-ray diffractometer (XRD, Bruker AXS, Karlsruhe, Germany), with $40 \mathrm{kV}$ and $30 \mathrm{~mA}, \mathrm{Cu}-\mathrm{K} \alpha$ radiation and a step size rate of $0.002 / \mathrm{s}$.

\section{Thermal Analysis}

Thermogravimetric (TG), derivative thermogravimetric (DTG) analysis of powdered samples was carried out using Perkin Elmer Diamond TG/DTA thermogravimetric analyzer. Thermograms of all samples were recorded at multiple heating rates of $2,5,10$ and $20{ }^{\circ} \mathrm{C}$ $\mathrm{min}^{-1}$ from ambient temperature to $700{ }^{\circ} \mathrm{C}$ under high purity nitrogen $(99.999 \%)$ at a flow rate of $20 \mathrm{~mL} \mathrm{~min}^{-1}$. The multiple heating rates were used in order to meet the requirement of activation energy calculation. Before starting each run, nitrogen was used to flush the furnace for 30 minute to create an inert atmosphere so as to avoid unwanted oxidation. Dried alumina powder was used as a reference material and ceramic sample holder was employed for taking thermograms. In order to ensure the uniformity of temperature of the sample and good reproducibility, small amounts (3-6 mg) were taken.

\section{Data processing and activation energy calculation}

TG curves were analyzed by using Pyris software from TG Analyzer and data was used in MS Excel and origin software to calculate activation energy (Ea) and correlation coefficient $\left(\mathrm{R}^{2}\right)$. The Ea values of samples were calculated by "model free" iso-conversional methods. The methods used in calculating activation energy at different conversions $(\alpha)$ were OzawaFlynn-Wall (O-F-W), Friedman and modified Coats-Redfern. The final equations used for calculation of $\mathrm{Ea}$ by different iso-conversional methods are given in Table 1. In these equations, $\beta$ is the heating rate, $\mathrm{R}$ is the universal gas constant, $\mathrm{A}$ is the pre-exponential factor, $\alpha$ is the degree of conversion and $\mathrm{g}(\alpha)$ is a function of $\alpha$. Using the value of slope of each line, Ea was calculated at different conversions.

Table 1. Kinetic methods used in calculating activation energy

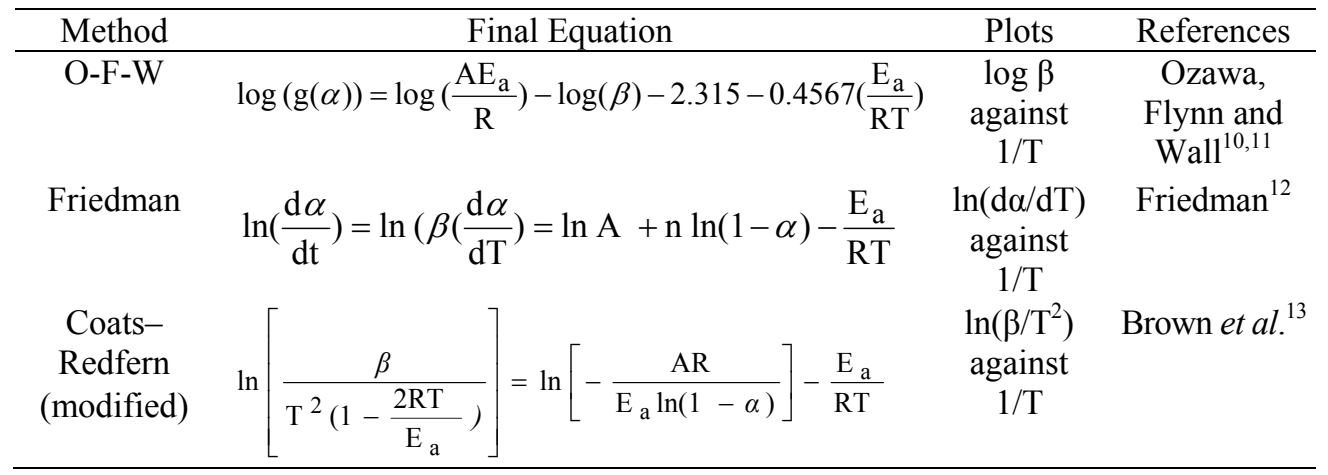




\section{Results and Discussion}

\section{Characterization of samples}

XRD curves of cellulose, CEASP and its metal complexes are shown in Figures 1-2. There are two sharp peaks at $2 \theta$ of $15^{\circ}$ and $22^{\circ}$ of intensity 1800 and 2500 a.u., respectively ${ }^{14}$. The patterns confirm the formation of the single phase glucose and no other extra phase peak is observed in the patterns. XRD studies of CEASP and its metal complexes shows sharp peak as $23^{\circ}$ for CEASP, two broad peaks at $23^{\circ}$ and $30^{\circ}$ for CEASP-Cd complex, only one broad peak at $23^{\circ}$ of CEASP-Mo complex and two peaks were observed for CEASP-Ce complex at $30^{\circ}$ (sharp) \& $48^{\circ}$ (broad). The change in $2 \theta$ values i.e. in crystalline phase of cellulose point towards the chemical modification in cellulose.

Weight percentage of different elements present in samples as observed from EDXS study, there is increase in $\mathrm{P} \%$ by a value $11 \%$ in CEASP sample as compared to cellulose that confirms the phosphorylation reaction. The weight \% of metals present in complexes of CEASP lie in the range $27-31 \%$ that indicate about the synthesis of metal complex formation.

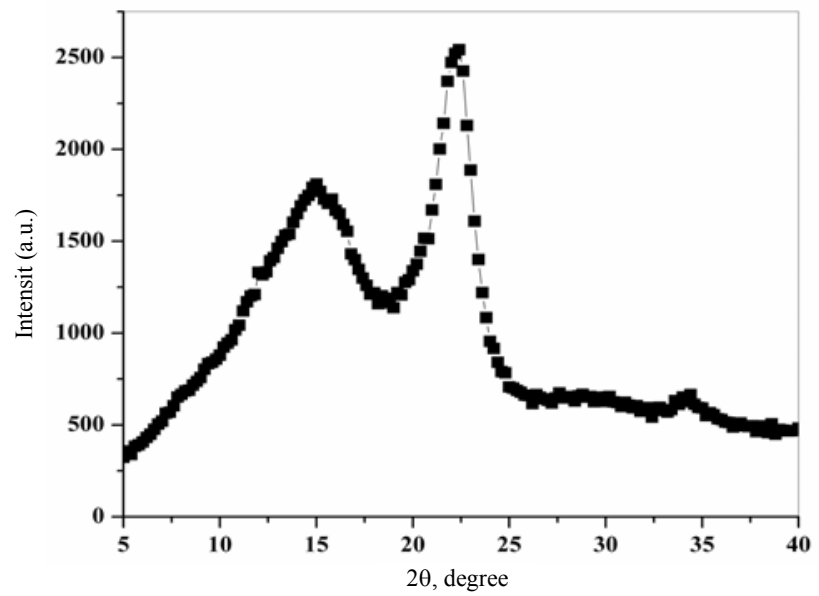

Figure 1. XRD of Cellulose

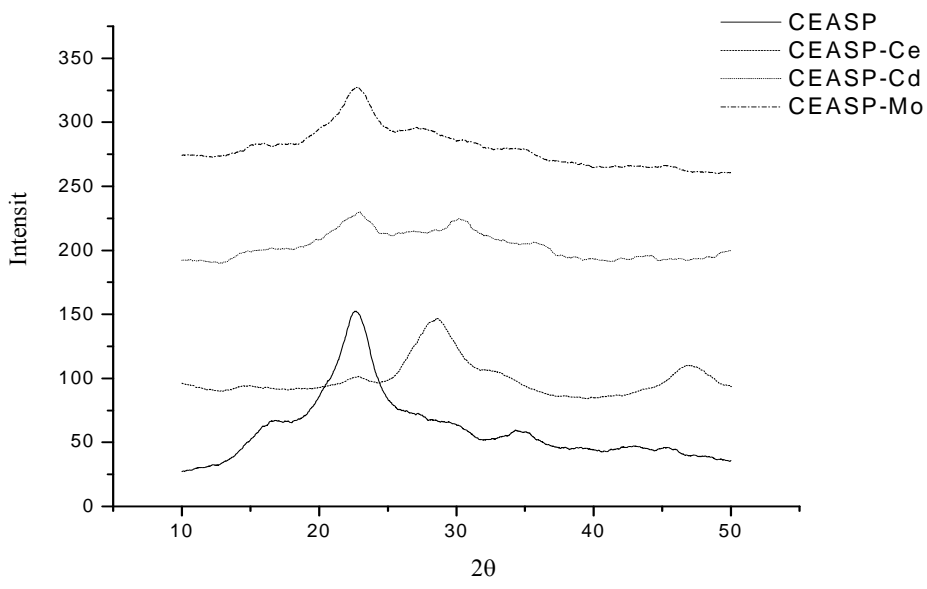

Figure 2. XRD of CEASP and its metal complexes 
The proposed route of CEASP synthesis is given in Scheme 1. In the IR spectrum, the main peaks in cellulose observed at $1250 \mathrm{~cm}^{-1}$ for $\mathrm{C}-\mathrm{O}$ out of plane stretching due to aryl group, $1625-1645 \mathrm{~cm}^{-1}$ due to aromatic rings and $3150-3500 \mathrm{~cm}^{-1}$ for $\mathrm{O}-\mathrm{H}$ stretching due to intramolecular hydrogen bonding ${ }^{15}$. Formation of CEASP was confirmed as additional bands were observed at 1250 (P-O-C stretching), 1170 ( $\mathrm{P}=\mathrm{O}$ stretching), 860 ( $\mathrm{P}-\mathrm{O}$ stretching), 620 (P-S stretching) and $3100-3200 \mathrm{~cm}^{-1}$ (N-H stretching) as compared to cellulose.

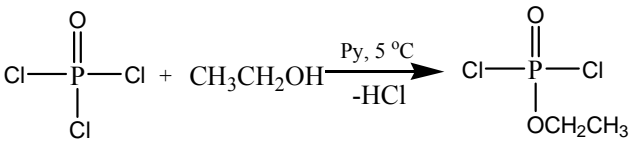<smiles>[SiH3]N=CCN[AsH3]</smiles>

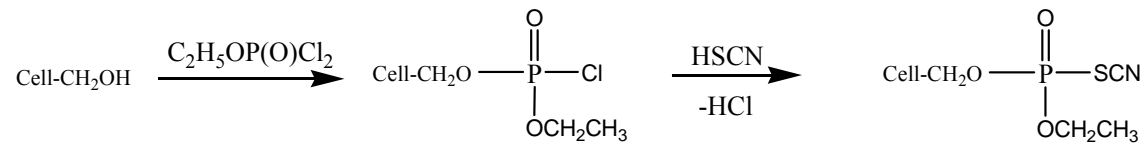

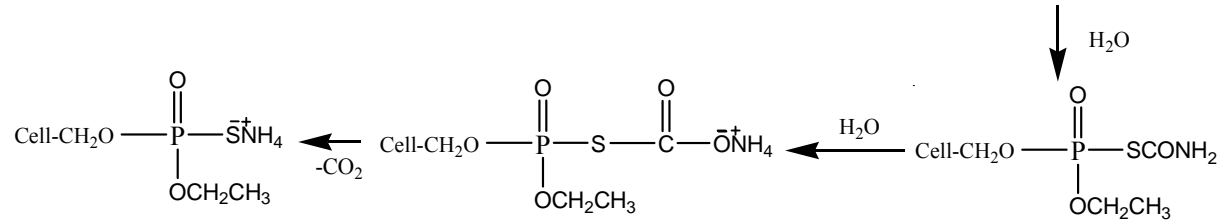

Scheme 1. Mechanism for CEASP

\section{SEM study}

SEM micrographs of cellulose, CEASP, CEASP-Cd and CEASP-Mo are given in Figures 3-6. The morphology of micrographs indicates that the surface of pure cellulose is even but surface of CEASP and its metal complexes is uneven ${ }^{16}$. This might be due to modification of cellulose and deposits of metal complexes.

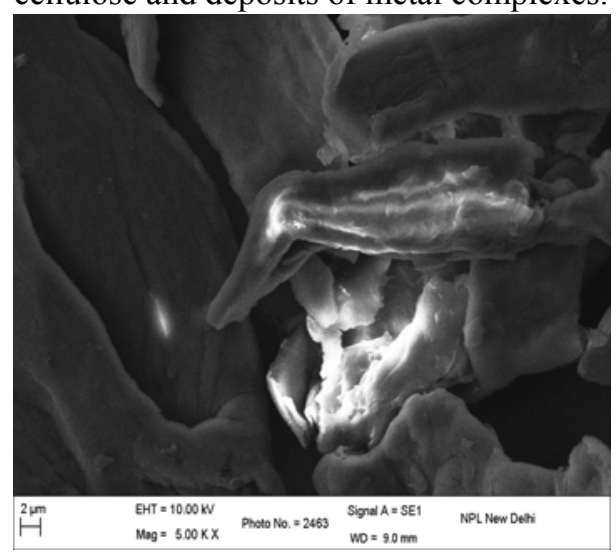

Figure 3. Micrograph of cellulose

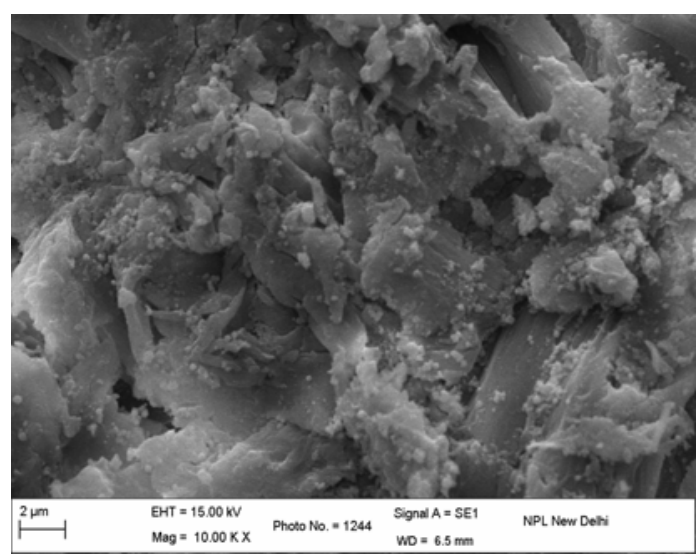

Figure 4. SEM micrographs of CEASP 


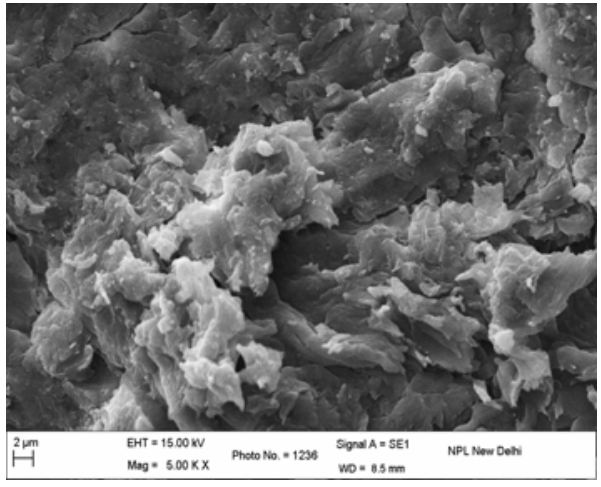

Figure 5. Micrograph of CEASP-Cd

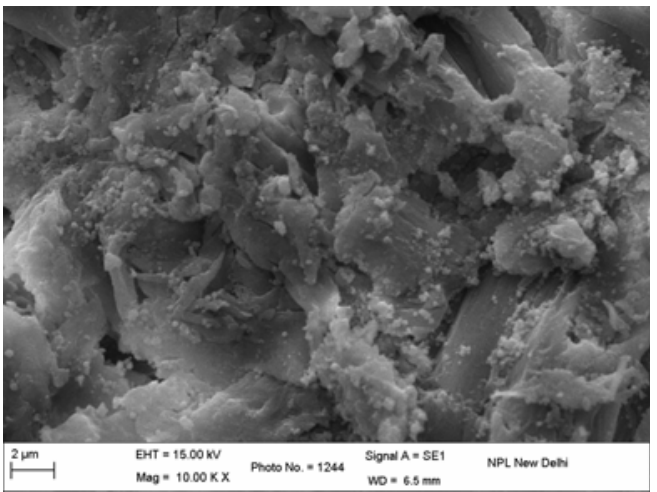

Figure 6. Micrographs of CEASP-Mo

\section{Thermal analysis}

TG curves profile of all samples at a heating rate of $10{ }^{\circ} \mathrm{C} \mathrm{min}^{-1}$ in nitrogen atmosphere is shown in Figure 7. The TG curves of samples at multiple heating rates are given in Figures 8-11 and Figure 12 represents the DTG curves of samples. The data observed from TG and DTG curves of samples at $10{ }^{\circ} \mathrm{C} \mathrm{min}-1$ is reported in Table 2 . TG curves of all samples shift towards higher temperature with increase in heating rate. This shift is due to different heat transfers and kinetic rates that delay the sample decomposition and is similar to result reported by Williums et al..$^{17}$. The onset degradation temperature $\left(\mathrm{T}_{\mathrm{o}}\right)$ of pure cellulose is $\sim 310^{\circ} \mathrm{C}$ and for CEASP is $234.9^{\circ} \mathrm{C}$. This notable decrease in to value might be due to acids produced from the dephosphorylation reactions that catalyses the decomposition process. The $T_{0}$ values for CEASP metal complexes are greater than CEASP and found to be lie in range $246-276{ }^{\circ} \mathrm{C}$. This might be due to presence of metal ions in the complex that increases the thermal stability of sample. Here it can be concluded that metals are increasing the thermal stability of CEASP. The mass loss (MLo) corresponds to onset degradation temperature for sample lie in the range $3-13 \%$ that is due to dehydration and decomposition process. The peak temperature (Tp) calculated from DTG curves of pure cellulose is $\sim 340^{\circ} \mathrm{C}$ and for CEASP it decreases to $247^{\circ} \mathrm{C}$. This decrease in Tp value might be due to acid catalysed reactions. The Tp for CEASP metal complexes is found to be in the range $277-313{ }^{\circ} \mathrm{C}$ which is greater than for CEASP.

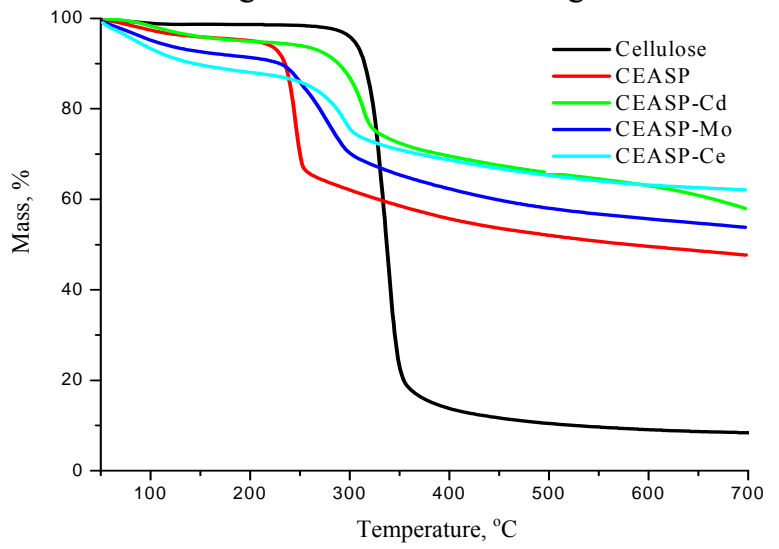

Figure 7. TG curves of Cellulose, CEASP and its metal complexes of $\mathrm{Cd}$, Mo and $\mathrm{Ce}$ at heating rate of $10{ }^{\circ} \mathrm{C} \mathrm{min}^{-1}$ in $\mathrm{N}_{2}$ atmosphere 


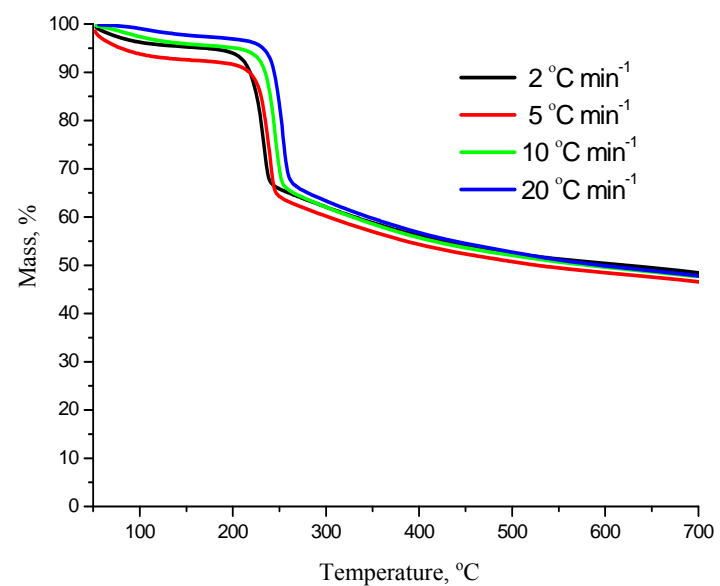

Figure 8. TG curves for CEASP at different heating rates of $2,5,10$ and $20{ }^{\circ} \mathrm{C} \mathrm{min}^{-1}$ in $\mathrm{N}_{2}$ atmosphere

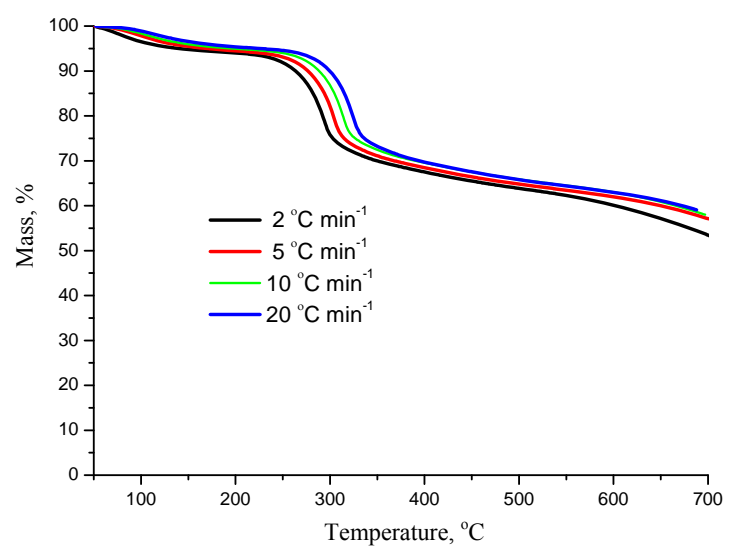

Figure 9. TG curve of CEASP-Cd complex at heating rates of 2, 5, 10 and $20{ }^{\circ} \mathrm{C} \mathrm{min}^{-1}$ in $\mathrm{N}_{2}$ atmosphere

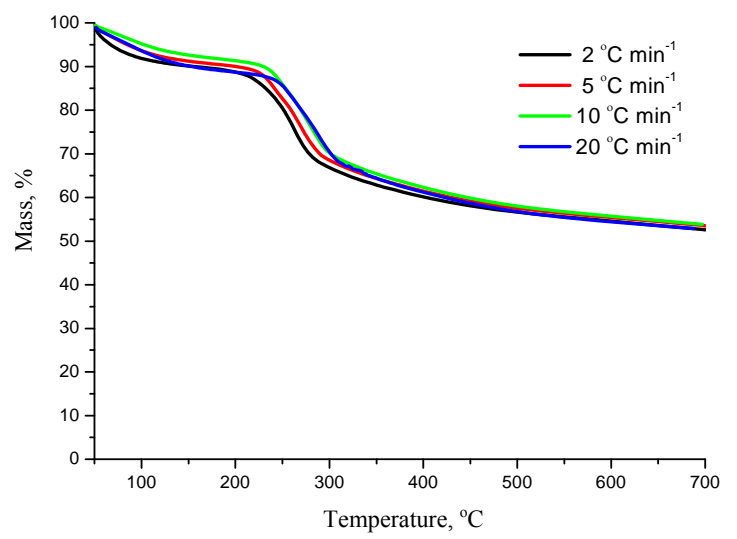

Figure 10. TG curve for CEASP-Mo complex at heating rates of $2,5,10$ and $20{ }^{\circ} \mathrm{C} \mathrm{min}^{-1}$ in $\mathrm{N}_{2}$ atmosphere 


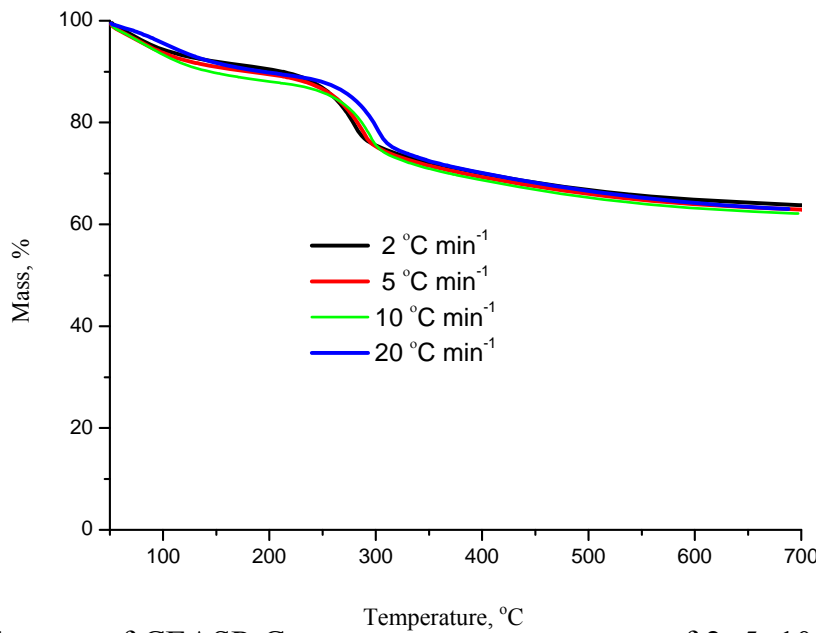

Figure 11. TG curve of CEASP-Ce complex at neatıng rates of $2,5,10$ and $20{ }^{\circ} \mathrm{C} \mathrm{min}^{-1}$ in $\mathrm{N}_{2}$ atmosphere

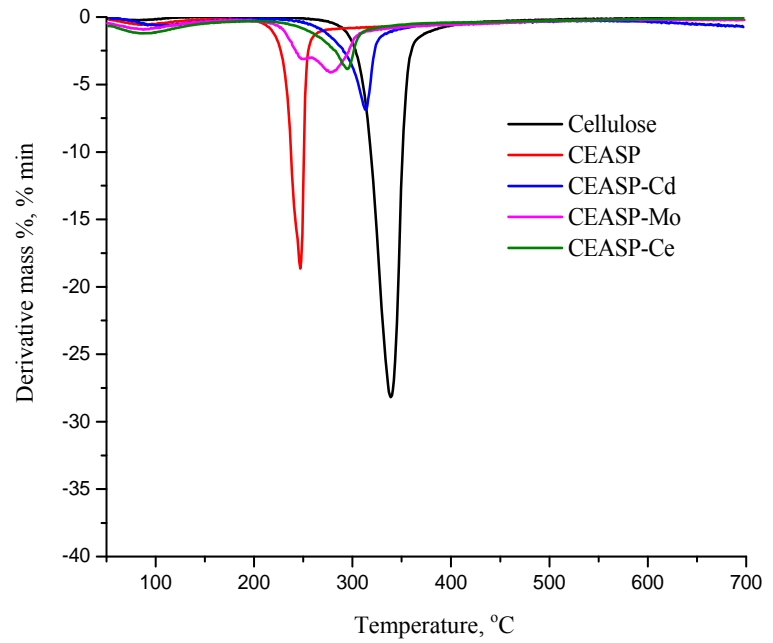

Figure 12. DTG curve of cellulose at heating rates of $2,5,10$ and $20{ }^{\circ} \mathrm{C} \min ^{-1}$ in $\mathrm{N}_{2}$ atmosphere

The mass loss (MLp) corresponding to Tp for complexes is lower (range 19-23\%) as compared to CEASP (25.5\%) and cellulose (55.3\%). Thus it is concluded from DTG study that metal complexes are thermally more stable than CEASP and pure cellulose which is also supported by $\mathrm{T}_{\mathrm{o}}$ data derived from TG curves.

TG, DTG data have great importance to evaluate the flame retardancy of samples ${ }^{18}$. The two parameters like maximum mass loss rate (MMLR) from DTG and char yield have premeditated from TG curves are used to evaluate flame retardancy character of samples. Higher value of char yield and lower value of MMLR point toward the improvement in the flame retardancy of sample. The parameter MMLR was calculated corresponding to peak maxima of DTG curves and char yield was calculated from TG curves at $650{ }^{\circ} \mathrm{C}$. The MMLR and char yield data is prearranged in Table 2. The MMLR value for pure cellulose is 
$28 \% \mathrm{~min}^{-1}$ and for CEASP its value decreases up to $18.5 \% \mathrm{~min}^{-1}$ that further decreases to $3-7 \%$ $\mathrm{min}^{-1}$ for metal complexes. The char yield for cellulose is $8.7 \%$ and its value increases to $48.6 \%$ for CEASP. Char yield for metal complexes further increases and lie in the range 54-63\%. The decrease in MMLR values and increase in char yield of CEASP and metal complexes as compared to cellulose show that depolymerization reaction in prepared samples are slower as compared to pure cellulose in nitrogen atmosphere. This might be due to formation of charred protective layer and incorporation of metal in the matrix of macromolecules that catalyses cross linking, leading to increased char yield and suppression of volatile products formed during combustion of polymers ${ }^{19}$. MMLR and char yield study led to a conclusion that all synthesized samples are showing good flame retardancy and among them CEASP-Ce sample is the best.

Table 2. Thermal decomposition parameters of cellulose and modified cellulose

\begin{tabular}{cccccccccc}
\hline Samples & $\begin{array}{c}\mathrm{T}_{\mathrm{o}}, \\
{ }^{\circ} \mathrm{C}\end{array}$ & $\begin{array}{c}\mathrm{ML}_{\mathrm{o}}, \\
\%\end{array}$ & $\begin{array}{c}\mathrm{T}_{\mathrm{S}}, \\
{ }^{\circ} \mathrm{C}\end{array}$ & $\begin{array}{c}\mathrm{ML}_{\mathrm{S}}, \\
\%\end{array}$ & $\begin{array}{c}\mathrm{T}_{\mathrm{P}}, \\
{ }^{\circ} \mathrm{C}\end{array}$ & $\begin{array}{c}\mathrm{ML}_{\mathrm{P}}, \\
\%\end{array}$ & $\begin{array}{c}\text { Temperature } \\
\text { Range, }{ }^{\circ} \mathrm{C}\end{array}$ & $\begin{array}{c}\text { MLR } \\
\% \text { min }^{-1}\end{array}$ & $\begin{array}{c}\text { Char } \\
\text { yield, } \%\end{array}$ \\
\hline Cellulose & 310.4 & 3.1 & 355 & 82.9 & 339.1 & 55.3 & $289-388$ & 28.0 & 8.7 \\
CEASP & 234.9 & 5.6 & 252.2 & 34.5 & 247.1 & 25.5 & $198-280$ & 18.5 & 48.6 \\
CEASP-Cd & 275.5 & 6.7 & 321.2 & 24.7 & 313.2 & 19.8 & $248-378$ & 6.8 & 60.9 \\
CEASP-Mo & 246.4 & 11.0 & 296.3 & 30.0 & 277.5 & 22.8 & $220-333$ & 4.0 & 54.7 \\
CEASP-Ce & 240.9 & 13.0 & 303.1 & 25.7 & 294.6 & 22.6 & $236-354$ & 3.8 & 62.5 \\
\hline
\end{tabular}

\section{Degradation Activation Energy}

The degradation activation energy of samples have been calculated using model free O-F-W, Friedman and modified Coats-Redfern methods. For illustration, the iso-conversional plot of O-F-W for CEASP and modified Coats-Redfern for CEASP-Mo are shown in Figures 13-14. The iso-conversional plot of O-F-W and modified Coats-Redfern showed a general trend of activation energy. The $\mathrm{Ea}$ and $\mathrm{R}^{2}$ values calculated by different methods at a particular conversion for all samples are summarized in Tables 3-5. The $\mathrm{R}^{2}>0.91$ were selected to calculate $\mathrm{Ea}$ at a particular $\alpha$ value. The iso-conversional plot of activation energy shows the general trend of activation energy. The fitted lines in iso-conversional plots of samples are parallel pointing the possibility of single order of degradation mechanism ${ }^{20,21}$.

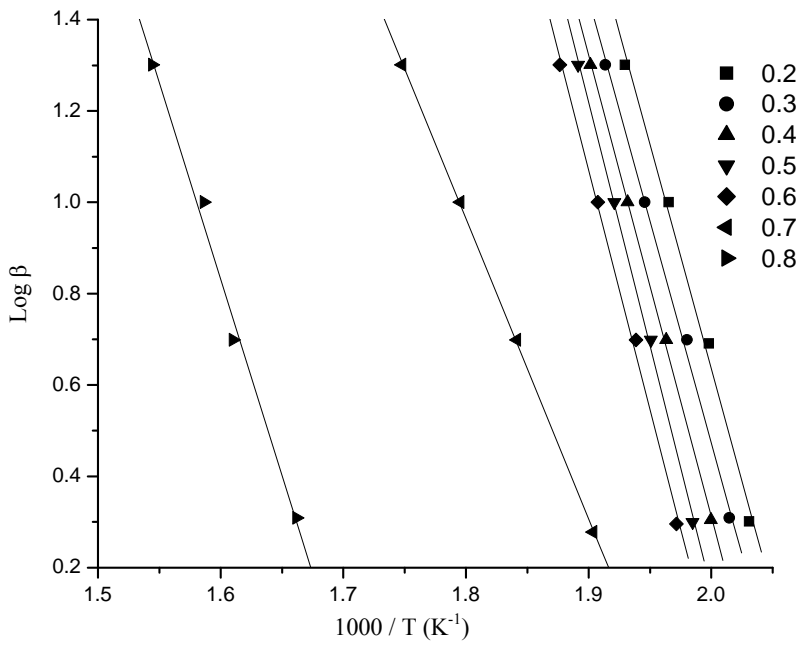

Figure 13. Iso-conversion plot of O-F-W method for CEASP at varying degree of conversion $(\alpha)$ 


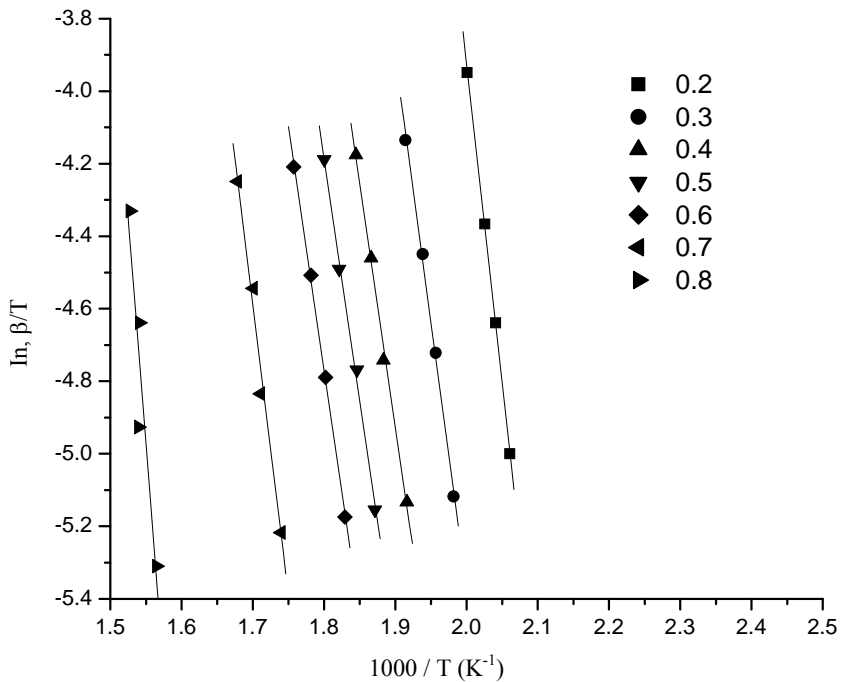

Figure 14. Plot of Coats-Redfern modified method for CEASP-Mo complex at varying degree of conversion

Table 3. Activation energy and correlation coefficient of samples calculated by Friedman method

\begin{tabular}{ccccccccccc}
\hline$\alpha$ & \multicolumn{3}{c}{ Cellulose } & \multicolumn{2}{c}{ CEASP } & \multicolumn{2}{c}{ CEASP-Cd } & \multicolumn{2}{c}{ CEASP-Mo } & \multicolumn{2}{c}{ CEASP-Ce } \\
\cline { 2 - 12 } & Ea & $\mathrm{R}^{2}$ & Ea & $\mathrm{R}^{2}$ & Ea & $\mathrm{R}^{2}$ & $\mathrm{Ea}$ & $\mathrm{R}^{2}$ & Ea & $\mathrm{R}^{2}$ \\
\hline 0.20 & 179.1 & 0.981 & 234.1 & 0.991 & 97.5 & 0.921 & - & - & - & - \\
0.25 & 156.8 & 0.974 & 234.2 & 0.997 & 166.4 & 0.918 & 94.9 & 0.924 & 34.15 & 0.910 \\
0.30 & 152.1 & 0.985 & 241.7 & 0.967 & 215.6 & 0.997 & 180 & 0.969 & 22.74 & 0.946 \\
0.35 & 148.7 & 0.981 & 201.7 & 0.996 & 191.2 & 0.964 & 201.7 & 0.926 & 137.9 & 0.953 \\
0.40 & 134.1 & 0.989 & 192.7 & 0.997 & 310.6 & 0.976 & 257.7 & 0.958 & 260.1 & 0.924 \\
0.45 & 132.6 & 0.976 & 247.3 & 0.965 & 280.6 & 0.936 & 281.4 & 0.953 & 330.9 & 0.956 \\
0.50 & 135.5 & 0.990 & 227.9 & 0.966 & 297.5 & 0.949 & 255 & 0.986 & 289.3 & 0.967 \\
0.55 & 139.8 & 0.985 & 197.4 & 0.971 & 336.6 & 0.940 & 207.5 & 0.912 & 322.7 & 0.965 \\
0.60 & 141.7 & 0.987 & 110.3 & 0.928 & 380.9 & 0.934 & 250 & 0.984 & 110.5 & 0.974 \\
0.65 & 140.8 & 0.988 & - & - & - & - & - & - & - & - \\
0.70 & 140.2 & 0.989 & 114.2 & 0.914 & 151 & 0.934 & 157.8 & 0.924 & 172.2 & 0.962 \\
\hline
\end{tabular}

Table 4. Activation energy and correlation coefficient of samples calculated by O-F-W method

\begin{tabular}{|c|c|c|c|c|c|c|c|c|c|c|}
\hline \multirow[t]{2}{*}{$\alpha$} & \multicolumn{2}{|c|}{ Cellulose } & \multicolumn{2}{|c|}{ CEASP } & \multicolumn{2}{|c|}{ CEASP-Cd } & \multicolumn{2}{|c|}{ CEASP-Mo } & \multicolumn{2}{|c|}{ CEASP-Ce } \\
\hline & $\mathrm{Ea}$ & $\mathrm{R}^{2}$ & $\mathrm{Ea}$ & $\mathrm{R}^{2}$ & $\mathrm{Ea}$ & $\mathrm{R}^{2}$ & $\mathrm{Ea}$ & $\mathrm{R}^{2}$ & $\mathrm{Ea}$ & $\mathrm{R}^{2}$ \\
\hline 0.20 & 161.3 & 0.981 & 160.4 & 0.986 & 175.9 & 0.986 & 90.7 & 0.951 & 80.4 & 0.906 \\
\hline 0.25 & 160.9 & 0.974 & 184.3 & 0.968 & 191.5 & 0.990 & 91.5 & 0.920 & 95.2 & 0.977 \\
\hline 0.30 & 158.0 & 0.985 & 197.6 & 0.975 & 201.6 & 0.990 & 195.2 & 0.910 & 100.4 & 0.936 \\
\hline 0.35 & 157.6 & 0.981 & 204.0 & 0.977 & 209.4 & 0.991 & 227.9 & 0.936 & 123.7 & 0.972 \\
\hline 0.40 & 156.5 & 0.989 & 209.2 & 0.978 & 214.4 & 0.992 & 246.7 & 0.935 & 248.7 & 0.966 \\
\hline 0.45 & 155.5 & 0.976 & 213.6 & 0.978 & 218.2 & 0.992 & 244.9 & 0.960 & 273.4 & 0.902 \\
\hline 0.50 & 154.3 & 0.990 & 218.9 & 0.977 & 228.1 & 0.986 & 238.6 & 0.977 & 275.1 & 0.951 \\
\hline 0.55 & 152.9 & 0.985 & 218.8 & 0.978 & 271.9 & 0.933 & 238.0 & 0.983 & 277.1 & 0.976 \\
\hline 0.60 & 151.9 & 0.987 & 213.2 & 0.970 & 295.1 & 0.917 & 238.9 & 0.983 & 284.6 & 0.977 \\
\hline 0.65 & 150.8 & 0.988 & 200.0 & 0.900 & - & - & - & - & - & - \\
\hline 0.70 & 150.6 & 0.989 & 156.6 & 0.951 & 190.2 & 0.988 & 252.7 & 0.921 & 323.3 & 0.902 \\
\hline
\end{tabular}


Table 5. Activation energy and correlation coefficient of samples calculated by modified Coats-Redfern method

\begin{tabular}{ccccccccccc}
\hline$\alpha$ & \multicolumn{2}{c}{ Cellulose } & \multicolumn{2}{c}{ CEASP } & \multicolumn{2}{c}{ CEASP-Cd } & \multicolumn{2}{c}{ CEASP-Mo } & \multicolumn{2}{c}{ CEASP-Ce } \\
\cline { 2 - 13 } & Ea & $\mathrm{R}^{2}$ & $\mathrm{Ea}$ & $\mathrm{R}^{2}$ & $\mathrm{Ea}$ & $\mathrm{R}^{2}$ & $\mathrm{Ea}$ & $\mathrm{R}^{2}$ & $\mathrm{Ea}$ & $\mathrm{R}^{2}$ \\
\hline 0.20 & 165.0 & 0.986 & 160.3 & 0.922 & 175.9 & 0.984 & 72.7 & 0.904 & 92.3 & 0.900 \\
0.25 & 162.9 & 0.989 & 185.3 & 0.965 & 192.1 & 0.989 & 87.9 & 0.982 & 105.2 & 0.946 \\
0.30 & 156.7 & 0.989 & 199.4 & 0.972 & 202.7 & 0.990 & 196.9 & 0.903 & 116.4 & 0.975 \\
0.35 & 156.6 & 0.987 & 206.1 & 0.975 & 210.8 & 0.992 & 231.1 & 0.931 & 120.6 & 0.945 \\
0.40 & 152.6 & 0.985 & 211.5 & 0.977 & 215.9 & 0.991 & 250.7 & 0.931 & 252.7 & 0.953 \\
0.45 & 155.3 & 0.984 & 216.1 & 0.976 & 219.9 & 0.985 & 248.7 & 0.957 & 278.4 & 0.901 \\
0.50 & 158.4 & 0.988 & 221.7 & 0.987 & 230.3 & 0.928 & 241.9 & 0.975 & 280.2 & 0.948 \\
0.55 & 154.8 & 0.983 & 221.5 & 0.978 & 276.3 & 0.901 & 245 & 0.981 & 282.2 & 0.974 \\
0.60 & 152.6 & 0.985 & 215.6 & 0.968 & 300.5 & 0.973 & 242 & 0.982 & 289.9 & 0.975 \\
0.65 & 151.2 & 0.985 & 173.6 & 0.962 & 119.5 & 0.973 & 250.3 & 0.972 & 300.3 & 0.918 \\
0.70 & 150.1 & 0.988 & 154.3 & 0.924 & 130.2 & 0.901 & 256 & 0.915 & 330.3 & 0.982 \\
\hline
\end{tabular}

The variation of activation energy with degree of conversion is shown in Figures 15-17. The activation energy of samples lie in range $72-282 \mathrm{~kJ} \mathrm{~mol}^{-1}$. From the graphs it is clear that activation energy of synthesized samples is more as compared to Ea values of pure cellulose in the conversion range 4-5.5 and for metal complexes Ea values are more than CEASP. The increased value of Ea for CEASP and metal complexes than cellulose might be due to formation of protective layer that result in increase in Ea required for the depolymerization process. High values of Ea in this range indicate about the extended thermal stability of metal complexes and CEASP in comparison to cellulose. However the Ea for metal complexes is more than CEASP that means metal complexes are thermally more stable than CEASP. The outcomes from activation energy studies are in line with the results obtained from TG, DTG studies.

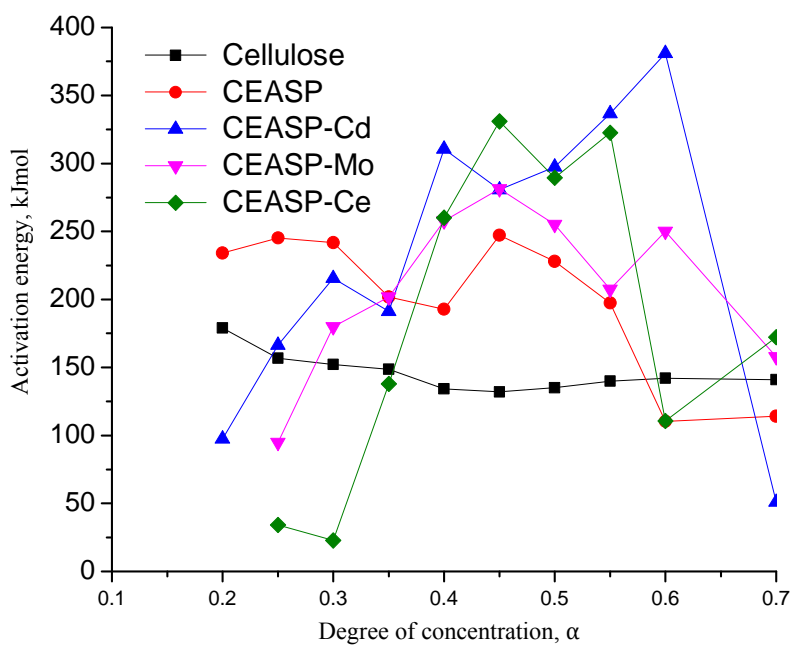

Figure 15. Variation of activation energy E vs. degree of conversion $\alpha$ for pyrolysis of all samples as calculated using Friedman method 


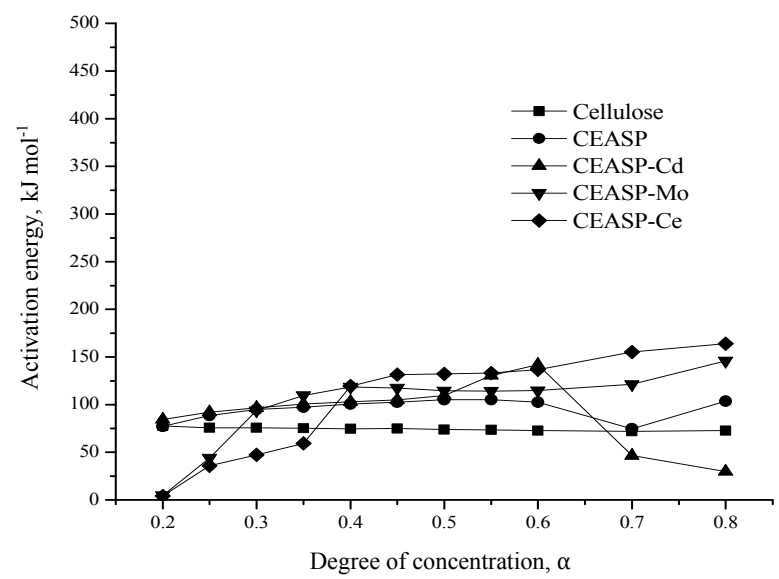

Figure 16. Relationship of activation energy E $v s . \alpha$ for pyrolysis of samples as calculated by O-F-W method

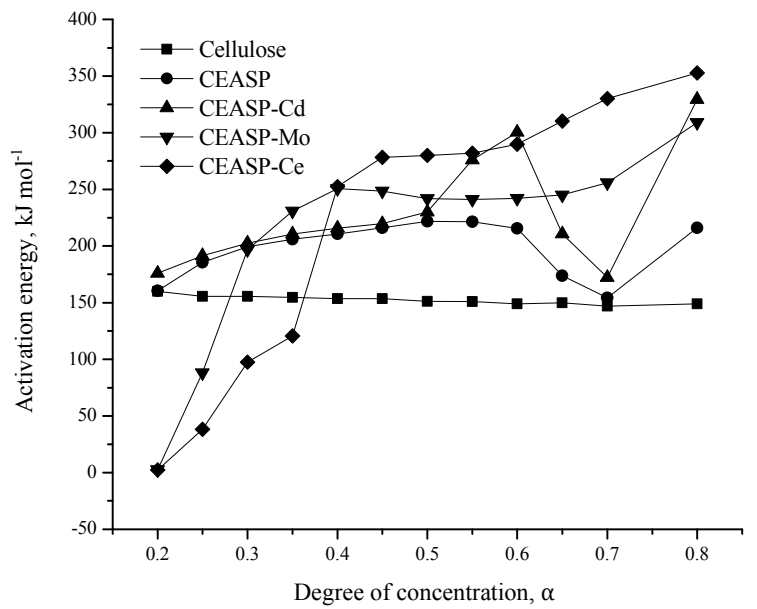

Figure 17. Relationship of activation energy E vs. $\alpha$ for pyrolysis of samples by CoatsRedfern modified method

\section{Conclusion}

The preparation of CEASP and its metal complexes have been characterized by IR, XRD, EDXS. The morphology of surface of sample by SEM shows that surface of synthesized sample is uneven as compared to pure cellulose that confirms the modification in cellulose chemically. The onset degradation temperature of CEASP is lower as compared to pure cellulose that might be due to release of acid that catalyses the decomposition process. The $\mathrm{T}_{\mathrm{o}}$ values for CEASP metal complexes is greater than CEASP and found to be lie in range $246-276{ }^{\circ} \mathrm{C}$. This might be due to formation of protective layer of metal that increases the thermal stability of sample. The MMLR value for pure cellulose is $28 \% \mathrm{~min}^{-1}$ and for CEASP its value decreases up to $18.5 \% \mathrm{~min}^{-1}$ that further decreases to $3-7 \% \mathrm{~min}^{-1}$ for metal complexes. The char yield for cellulose is $8.7 \%$ and its value increases to $48.6 \%$ for CEASP. Char yield for metal complexes further increases and lie in the range 54-63\%. MMLR and char yield study led to a conclusion that all synthesized samples are showing good flame retardancy 
and among them CEASP-Ce sample is the best. Thermal degradation activation energy deliberated using model free kinetic methods viz Friedman, Ozawa-Flynn-Wall (O-F-W) and modified Coats- Redfern lie in range $72-282 \mathrm{~kJ} \mathrm{~mol}^{-1}$. Activation energy of synthesized samples is more as compared to Ea values of pure cellulose in the conversion range 4-5.5 and metal complexes Ea values are more than CEASP. The aforesaid study helps to conclude that metal complexes of CEASP are thermally more stable than CEASP and cellulose and such type of derivatization could be proved an good flame retardant for cellulose.

\section{Acknowledgement}

Authors are thankful to Chairman, Department of Chemistry, Kurukshetra University, Kurukshetra for providing necessary lab facilities. Authors are also thankful to authorities of National Physical Laboratory, New Delhi for carrying out EDXS, XRD and SEM analysis.

\section{References}

1. www.delhi.gov.in Delhi Fire Service, Accessed on 20 September 2014

2. Cabrales L and Abidi N, $J$ Therm Anal Calorim., 2010, 102, 485-491.

3. Liu Y L, Hsiue G H, Lan C W and Chiu Y S, Polym Degrad Stab., 1997, 56(), 291299; DOI:10.1016/S0141-3910(96)00177-2

4. $\quad$ Singh R, Arora S and Lal K, Thermochim Acta, 1996, 289(1), 9-21; DOI:10.1016/S0040-6031(96)03057-2

5. Dahiya J B and Rana S, Polym Int., 2004, 53(7), 995-1002; DOI:10.1002/pi.1500

6. Dahiya J B and Sushila Rana, Indian J Chem., 2005, 44A, 2024-2029.

7. Bhagwan J, Arora S and Lal K, J Polym Mater., 1990, 7, 231-237.

8. Vyazovkin S and Wight C A, Thermochim Acta, 1999, 340/341, 53-68; DOI:10.1016/S0040-6031(99)00253-1

9. Vyazovkin S, Thermochim Acta, 2000, 355(1-2), 155-163; DOI:10.1016/S00406031(00)00445-7

10. Ozawa T, Bull Chem Soc Jpn., 1965, 38(11), 1881-1886; DOI:10.1246/bcsj.38.1881

11. Flynn J H and Wall L A, J Res Nat Bur Stand., 1966, 70A, 487-523.

12. Friedman H L, J Polym Sci Part C-Polym Symp., 1964, 6, 183-195.

13. Brown A L, Dayton D C and Daily J W, Energy Fuels, 2001, 15(5), 1286-1294; DOI:10.1021/ef010084c

14. Ardizzone S, Dioguardi F S, Mussini T, Mussini P R, Rondinini S, Verecelli B and Vertova A, Cellulose, 1999, 6, 57-69; DOI:10.1023/A:1009204309120

15. Kumar A, Negi Y S, Choudhary V and Bhardwaj N K, J Mater Phy Chem., 2014, 2(1), 1-8.

16. Zhao H, Kwak J H, Zhang Z C, Brown H M, Arey B W and Holladay J E, Carbohydr Polym., 2007, 68(2), 235-241; DOI:10.1016/j.carbpol.2006.12.013

17. Williums P T and Besler S, Renew Energy, 1996, 7(3), 233-250; DOI:10.1016/09601481(96)00006-7

18. Arora S, Kumar M and Kumar M, J Therm Anal Calorim., 2012, 107, 1277-1286.

19. Arora S, Kumar M and Kumar M, J Compos Mater., 2013, 47(16), 2027-2038; DOI:10.1177/0021998312453865

20. Arora S, Lal S, Kumar S, Kumar M and Kumar M, Arch Appl Sci Res., 2011, 3(3), 188-201.

21. Shafizadeh F and Bradbury A G W, J Appl Polym Sci., 1979, 23, 1431-1442. 